\title{
The Geomed Project: the state of the art
}

\author{
Maria Antonia Brovelli( $\left.{ }^{1}\right)$ and Fernando Sansó $\left({ }^{2}\right)$ \\ (1) I.Ge.S., Istituto Nazionale di Geofisica, Milano, Italy \\ $\left.{ }^{2}\right)$ D.I.I.A.R., Politecnico di Milano, Italy
}

\begin{abstract}
The paper presents the program of an International Project, supported by the European community, aiming at the determination of the geoid and the sea surface topography in the Mediterranean area. The Project, named Geomed, involves seven scientific groups from six countries: University of Madrid, University of Thessaloniki, University of Copenhagen, University of Helsinki, Technical University of Graz, the National Survey and Cadaster of Denmark and the International Geoid Service of Milan. The first results obtained are illustrated, the state of the art of the project and its perspectives are discussed.
\end{abstract}

Key words Mediterranean Sea - geoid - sea surface topography

\section{Introduction}

It was more than one year ago that seven scientific groups from six nations (Spain, Italy, Austria, Greece, Denmark and Finland) met with the purpose of setting up an international cooperative effort to determine the geoid and the sea surface topography (SST) on the Mediterranean sea. The geoid, or better some equipotential surface of the gravity field suitably fitting the physical surface of the Mediterranean, is determined as the basic surface in geodesy to which orthometric heights are referred; a good knowledge of the geoid could for instance allow a much better reattachment of the different national height systems usually conventionally referred to some tide gauges as zero points.

The SST, i.e. the stationary height of the sea above the ellipsoid, is a fundamental parameter of physical oceanography strongly related to the steady circulation pattern involving surface as well as deep water streams (geostrophic flow) (Wunsch, 1993).

These two surfaces, i.e. the geoid and the SST, can nowadays be separated because the geoid can be determined by measurements related to the gravity field only, while the physical surface of the ocean can be achieved by the radaraltimetric measurements performed by dedicated satellite missions (like the now flying ERS1 and Topex Poseidon satellites) after several corrections (firstly the radial orbital correction) and time averaging are applied (Balmino, 1993 and Zlotnicki, 1993).

In the most advanced approaches the global analysis of the available data sets (gravimetric, altimetric, satellite tracking, etc.) proceeds as follows (Rapp, 1989b):

1) let us call $\Delta g$ the field of mean block values of gravity anomalies usually known on land areas (e.g. over $1^{\circ} \times 1^{\circ}$ blocks), $T$ the anomalous gravity potential, $t$ the stationary sea surface topography, $h$ the measured height of the sea above the ellipsoid (already corrected by the time varying components), $T_{P}$ a reference (prior) model of the anomalous potential developed in spherical harmonics up to some degree $N_{\max }\left(e . g . N_{\max }=50\right)$ and derived from the adjustment of pure satellite tracking data, $\xi_{r}$ the radial orbital error of the altimetric satellite orbit computed from $T_{P}$ (this error is due to both imperfect knowledge of the initial state and errors contained in $T_{P}$ propagated to 
the orbit). We can write observation equations of the form:

$$
\begin{gathered}
\Delta g=-\frac{\partial T}{\partial r}-\frac{2}{r} T+v_{g} \\
h=\frac{T}{\gamma}+t+\xi_{r}+v_{n} \\
T_{P}=T+v_{T}
\end{gathered}
$$

where $\gamma$ is the normal gravity and $v_{g}, v_{n}, v_{T}$ are independent noises. Equation (1.1) holds on continental areas, while (1.2) holds on oceanic areas.

2) in the above equations usually $T$ is modelled as a sum of spherical harmonics up to the same degree $N_{\max }$ as $T_{P}, t$ is also represented by some truncated development, e.g. again by spherical harmonics up to some degree which in principle can be as high as $N_{\max }$ but usually is much lower (e.g. degree 12 or $20), \xi_{\text {r }}$ is also parameterized by a small number of parameters (e.g. $5 \sim 6$ ) over some time span (e.g. 1 day) in consideration of the fact that most of the power of this perturbation is known to be concentrated at the frequencies of once per rev and twice per rev (Wagner, 1989); all these unknowns are then estimated by applying a big least squares process to (1.1), (1.2) and (1.3) where, as one can easily recognize, $\xi_{r}$ is separated from $T$ and $t$ as it is the only time varying unknown, while $T$ is separated from $t$ mainly by virtue of the equations (1.1) and (1.3). All this happens at the degree of resolution given by $N_{\max }$ which is supposed to be enough to get a good estimate of $t$ and $\xi_{r}$.

3) Once $t$ and $\xi_{r}$ are known, track by track, they are subtracted from $h$ and block averaged to obtain estimates of $T$ mean values with a much higher resolution; from the $\Delta g$ mean values on land and $T$ mean values on sea one can derive high degree global models (e.g. up to $N_{\max }=360$ ) of $T$ by applying one of several known techniques (see for instance Rapp, 1993 or Brovelli and Migliaccio, 1993 or Sansó, 1993). This approach, although crit- icizable in some point, has certainly contributed an enormous improvement in the knowledge of global gravity field models. Unfortunately it cannot contribute as much in an area like the Mediterranean for two reasons:

a) the time dependent pattern of the sea surface is generally more complicated in closed seas than in open oceans where simpler tidal corrections hold;

b) the orbital corrections $\xi_{r}$ are more difficult to be estimated because of the shortness of the arcs which cannot last longer than few minutes before hitting continental areas. Moreover, the bad performance of global models on Eastern European countries (due to the non availability of gravity material there) makes the radial orbital error to display systematic effects and larger values (Knudsen and Brovelli, 1993). On such a sea there are however many gravity measurements available derived from marine gravimetry; this allows an independent computation of the gravimetric geoid which compared with the stationary surface rising from altimetric measurements can supply the sought SST. Very similar reasons and reasonings apply to the case of the Baltic Sea and this, beyond the scientific and personal closeness of the groups, is another justification for their cooperation.

We conclude this section by mentioning that also other groups have declared their interest for the project and cooperate directly or indirectly in it. They are: CERGA - France (Dr. F. Barlier), University of Barcellona (Dr. M.A. Andreu), Institut of Cataluña (Dr. I. Colomina), General Command of Mapping, Geodetic Computing - Ankara (Dr. A. Ayhan)

\section{Data}

We try to summarize in this section the type of data we have been able to collect till now focusing on their validation and on the need of new data to solve some ambiguous case. The main data files used for the purpose of Geomed concern:

Marine gravity data - These are free air anomalies given on the sea surface (fig. 1a-c), 
mainly derived by digitizing the famous maps by Morelli (Morelli, 1970; Allan and Morelli, 1971; Morelli et al., 1975a, Morelli et al., 1975b; Morelli et al. 1975c; Arabelos, 1980; Arabelos et al., 1987; Arabelos and Tscherning, 1988; Arabelos and Tziavos, 1989). Other gravity files are now available and in future they will be compared with the above for the scope of validation. By the way the actual data have all been scrutinized and essentially submitted to internal validation, so that doubious or possibly spourious data are now properly flagged in our files.

Land gravity data - We have (available) the national archives of Spain, Portugal and Italy. The Greek gravity data are not open, but they can be used by the Thessaloniki University in computations of the geoid in the Eastern Mediterranean. A few more data must be added to these, mainly provided by the Bureau Gravimetrique International which is considering to deliver a set of low resolution gravity for France. Moreover, there is a possibility to get similar data for Northern Africa from the University of Leeds (table I).

Digital terrain models - These include both topographic heights on land and the bathymetry of Mediterranean (fig. 2a-c). As for land data, only a small part of what would be needed with the proper resolution is available. On the other hand on the whole region, including bathymetry, we have two global mod-

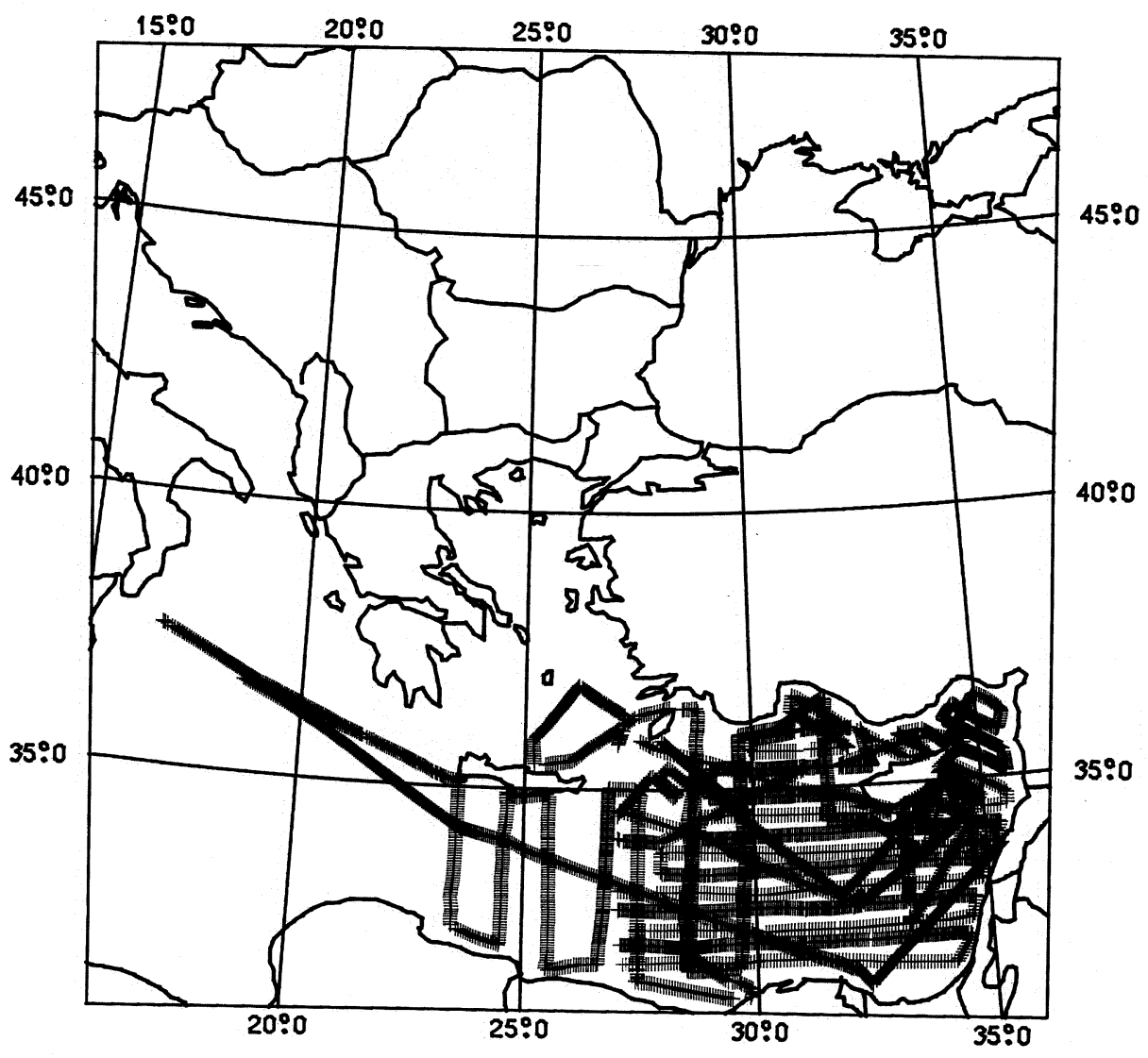

Fig. 1a. Position of the free air gravity anomaly observation points in the Eastern Mediterranean. 


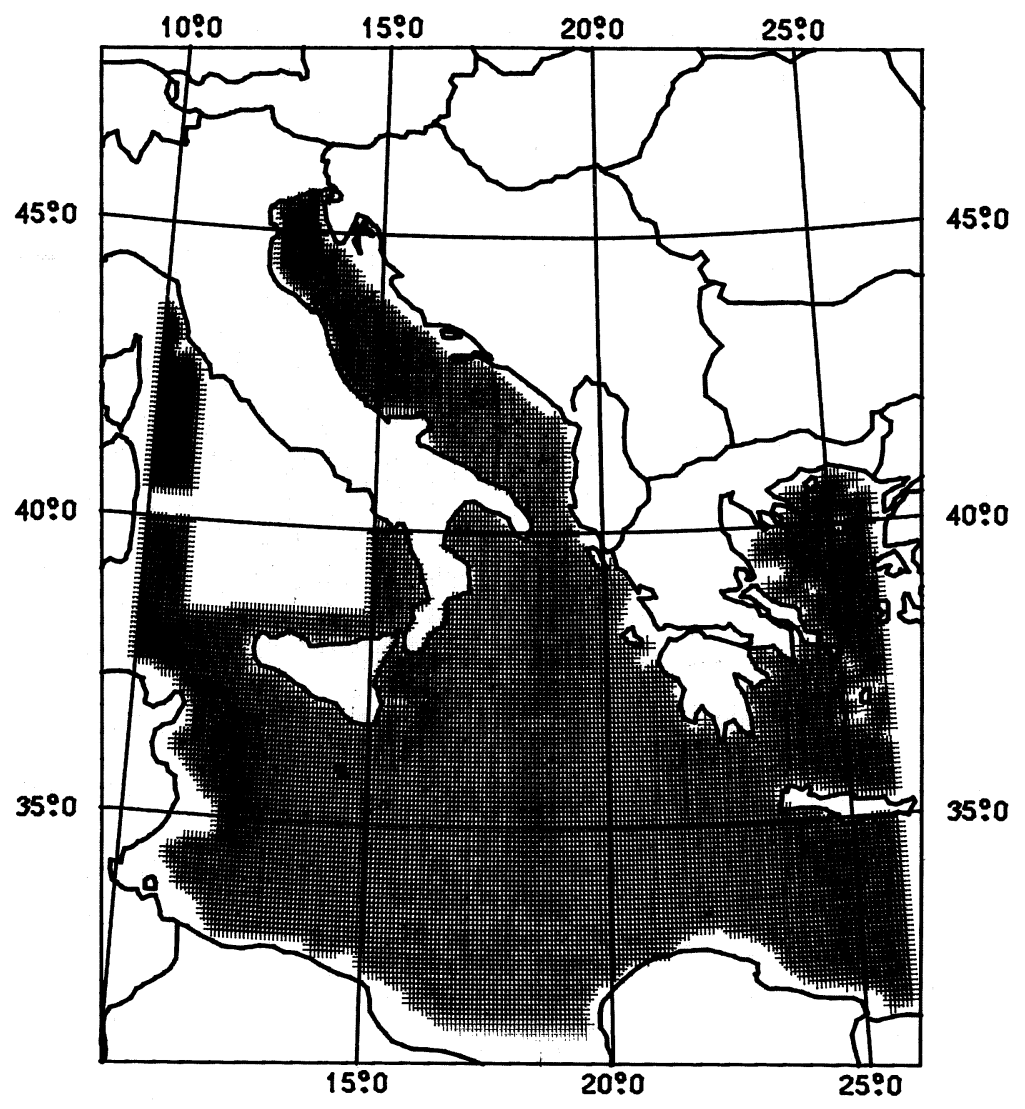

Fig. 1b. Position of the free air gravity anomaly observation points in the Central Mediterranean.

els, namely TUG87 and ETOPO5U both with a resolution of $5^{\prime} \times 5^{\prime}$.

The bathymetric maps of Morelli (resolution $5^{\prime} \times 7.5^{\prime}$, equidistance $200 \mathrm{~m}$ ) are also available in a digitized form thanks to the work of the Thessaloniki group.

Some work has been already done by using the TUG87 Model, however there are several doubts about its effectiveness due to a recent experience in the computation of the geoid in Italy, where it was shown that there are large discrepancies with the national DTM particularly in Southern Italy. Furthermore looking at any contour map, it seems quite obvious that it is unrealistically too flat in the whole Central Mediterranean; the good point on the oth- er hand is that there seems to be a fair agreement with the shore line and with the islands locations, proving that in applying a removerestore technique the highest frequency contribution to the geoid should be possibly guessed. Some work will be done in the next future in order to obtain an improved bathymetry by merging the existing data.

Altimetric data - We have collected the available altimetric data for the Mediterranean concerning the Seasat mission (fig. 3) as well as the Geosat mission (fig. 4), the latter restricted to the (ERM) Exact Repeat Mission (of a 17 day period) for the first 22 repetitions. These data have already been cleaned and processed in global adjustments by the 


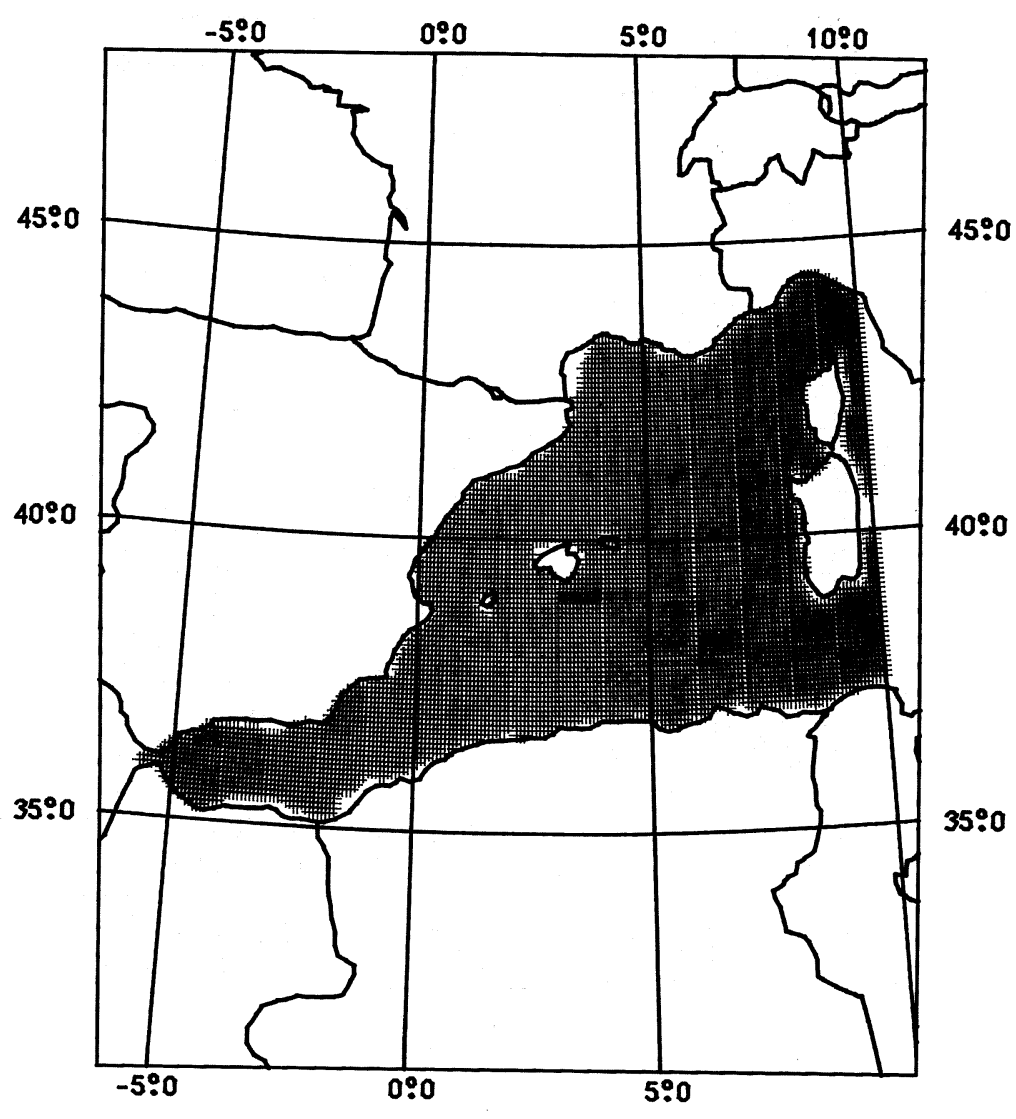

Fig. 1c. Position of the free air gravity anomaly observation points in the Western Mediterranean.

OSU University and in particular Geosat data have been corrected for the radial orbital error (Wang and Rapp, 1990). Naturally the correction for the radial orbital error in a global treatment suffers from the drawbacks we have already discussed in section 1 , as a local postprocessing has made clear. A new altimetric data set is now in the process of being collected and validated, namely that produced by the ERS1 mission; at the moment our files include the $\operatorname{ERM}(1-4)$ with a 35 day period (fig. 5) and the ERM(1-4) with a 3 day period (fig. 6).

Global geopotential models - Many global models are available in the Geomed Files, including IfE 88, OSU78, GPM2, OSU81, OSU86E, OSU86F, OSU89A, OSU89B,
OSU91A, DGFI92A, GEM10C . All these models have been tested statistically in the area of interest against gravity or altimetric data to decide which one could conveniently represent the data locally. At the end the choice has been for OSU91A (fig. 7a-c) as, although its performance is comparable to that of IfE88, it is credited to have superior global representativity (Rapp et al., 1991). Beyond these data, which are essential in computing either the gravimetric geoid or the stationary sea surface, other two data sets are currently collected in the Geomed Project as, so to say, subsidiary data, namely:

Tide gauge data - These are currently corrected by the Madrid and the Thessaloniki 
Table I. Number of available land gravity data (free air anomalies) in the Mediterranean area.

\begin{tabular}{lc}
\hline \hline Country & $\begin{array}{c}\text { Number of gravity } \\
\text { observations }\end{array}$ \\
\hline Italy & 23633 \\
Spain & 27692 \\
Portugal & 3859 \\
Egypt & 3219 \\
Morocco & 5711 \\
Algeria & 9725 \\
Libya & 705 \\
Tunisia & 156 \\
Jordan & 988 \\
Syria & 108 \\
Turkey & 226 \\
Greece & 217 \\
Former Yugoslavia & 13 \\
\hline
\end{tabular}

groups and attempts are now made to set up an empirical tidal model for the Mediterranean, split into 3 basins (Western, Central, Eastern);

Geophysical data - In particular we have collected information on the Moho depth to be able to smooth as much as possible the gravity field and to be able to predict it as accurately as possible. The Graz group has already performed some experiments in this direction.

\section{Methods and first results}

In this section we try to summarize the different methods proposed to solve our problem as well as the first results obtained, trying to make it clear which are the problems still open.

\subsection{For altimetry only}

This treatment is essentially an adjustment of cross-over values based on the observation equations

$$
h=(N+t)+\left(\xi_{r}+\tau\right)+v
$$

where $N=T / \gamma, t, \xi_{r}$ have the same meaning as in (1.2), while $\tau$ is a time varying component. Let us assume that $\xi_{r}$ and $\tau$ are so smooth that on a time span of a few minutes (so long can last at most a track on the Mediterranean before hitting a land) they can be well approximated by a linear function of time

$$
\xi_{r}+\tau=a T+b
$$

this is certainly true for $\xi_{r}$ (Schrama, 1989) and probably true, at least roughly, for $\tau$ when the subsatellite point is not too close to a coast.

Due to the very regular shape of the satellite orbit, which is close to a circle, in (3.2) the variable time $T$ can be substituted with longitude $\lambda$.

Now assume also that the observation (3.1) refers exactly to a point where two tracks cross each other (if this is not the case one can always perform an interpolation along the track), then since $(N+t)$ is the same in both tracks $i$ and $j$ we can write

$h_{i}-h_{j}=\left(a_{i} \lambda+b_{i}\right)-\left(a_{j} \lambda+b_{j}\right)+v_{i j}$

A system of equations of the type (3.3) can be adjusted by a least squares approach once the relevant rank deficiency problem is solved. In practice one can show that a bilinear surface $(z=A x y+B x+C y+D$ in planar coordinates) cannot be determined by this system of equations so that some constraint has to be imposed (Barzaghi et al., 1990). The most convenient of such constraints is to minimize the sum of the squares of the differences:

$$
h_{i}-N_{\text {Mod }}-\left(a_{i} \lambda+b_{i}\right)=\Delta_{i}
$$

on condition that realistic weights be chosen for (3.4) (on this subject cf. Barzaghi et al., 1991).

It is interesting to observe that to strengthen the solution also different data sets can be adjusted, while «almost» coinciding tracks can be stacked together (collinear analysis) to obtain stronger profiles. 

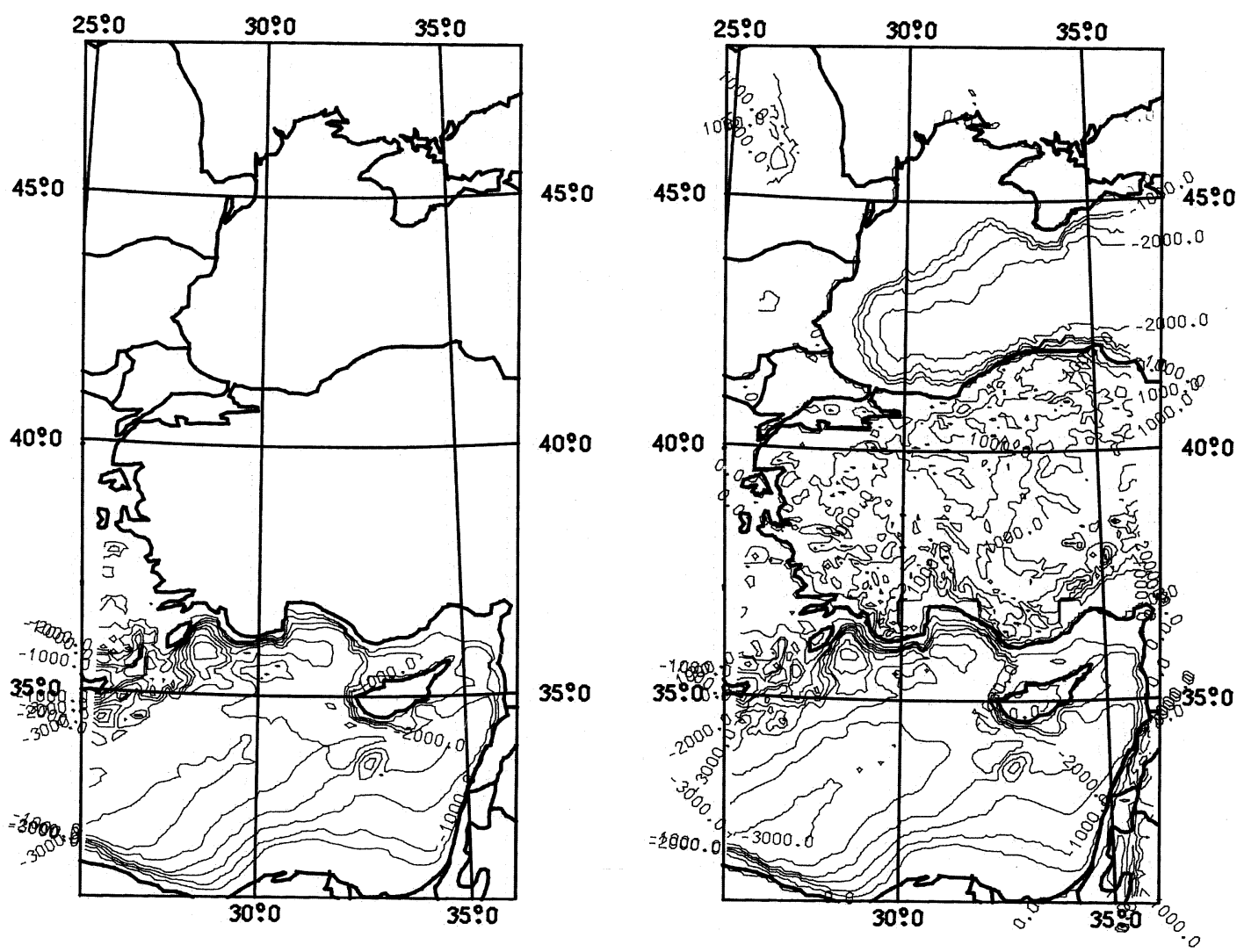

Fig. 2a. Bathymetry of the Eastern Mediterranean according to digitized Morelli's map (left); ETOPO5U digital terrain model on sea and land (right) in the same area (contour interval $=500 \mathrm{~m}$ ).

In this way for instance an altimetric geoid for the Mediterranean has been computed by the Copenhagen and the Milan groups jointly from the available Seasat and Geosat data.

To perceive the effectiveness of the adjustment we can say that (Knudsen and Brovelli, 1993) from raw to adjusted data we have discrepancies $\Delta$ with the model (see equation (3.4)) with standard deviation going from 60 $\mathrm{cm}$ down to $36 \mathrm{~cm}$ and, even more important, crossover residuals $v$ (see (3.3)) with s.d. decreasing from $30 \mathrm{~cm}$ down to $5 \mathrm{~cm}$.

\subsection{The gravimetric geoid}

This can be computed in several different ways following the classical approach of the collocation method. In any case it is convenient first of all to modify the gravity data set by a process, named «remove-restore», which has the effect to smooth and regionalize the gravity field.

First of all, the free air anomalies $\Delta g_{F}$ are filtered at the long wavelengths by subtracting the anomalies computed by a global model $\Delta g_{M}$; with this manipulation the data set is regionalized in the sense that in principle it becomes devoid of signals at wavelengths larger than or even comparable with the sides of the window where the data are given.

The remaining signal is therefore well estimable with the available data and we can neglet the data outside the window, which are not available.

Second, we considerably reduce the power 


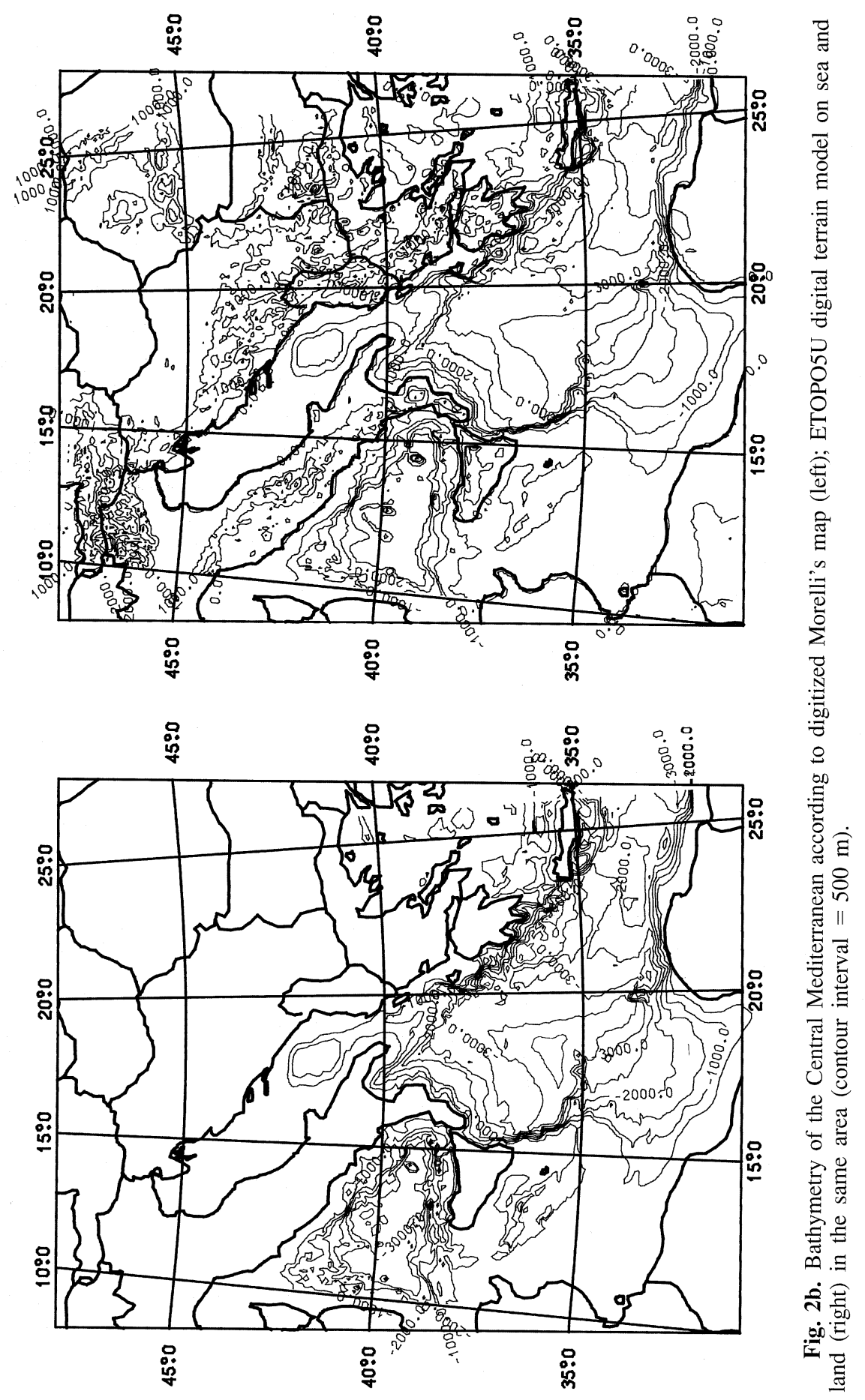




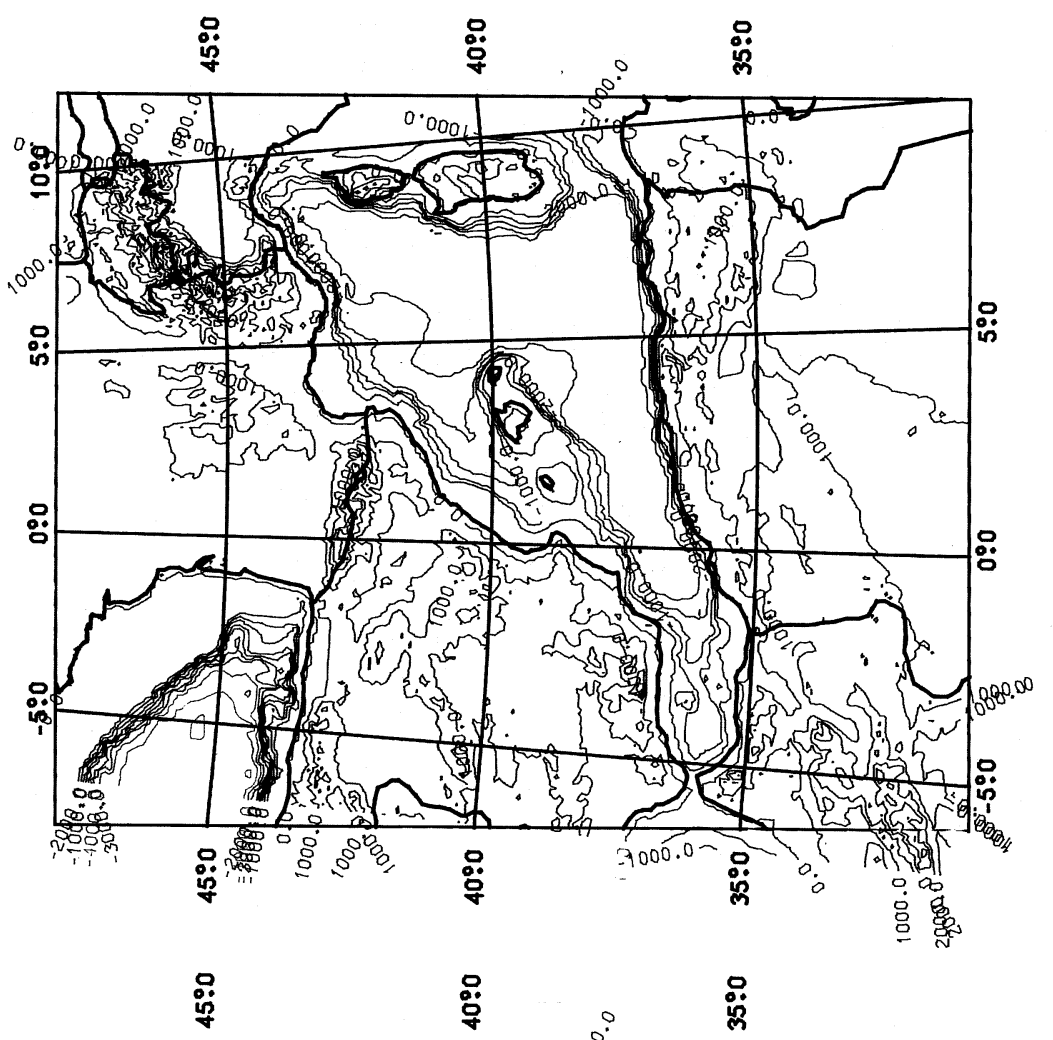

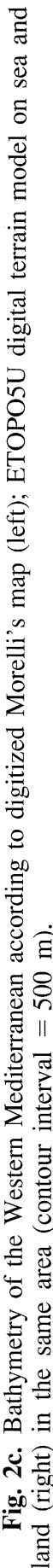




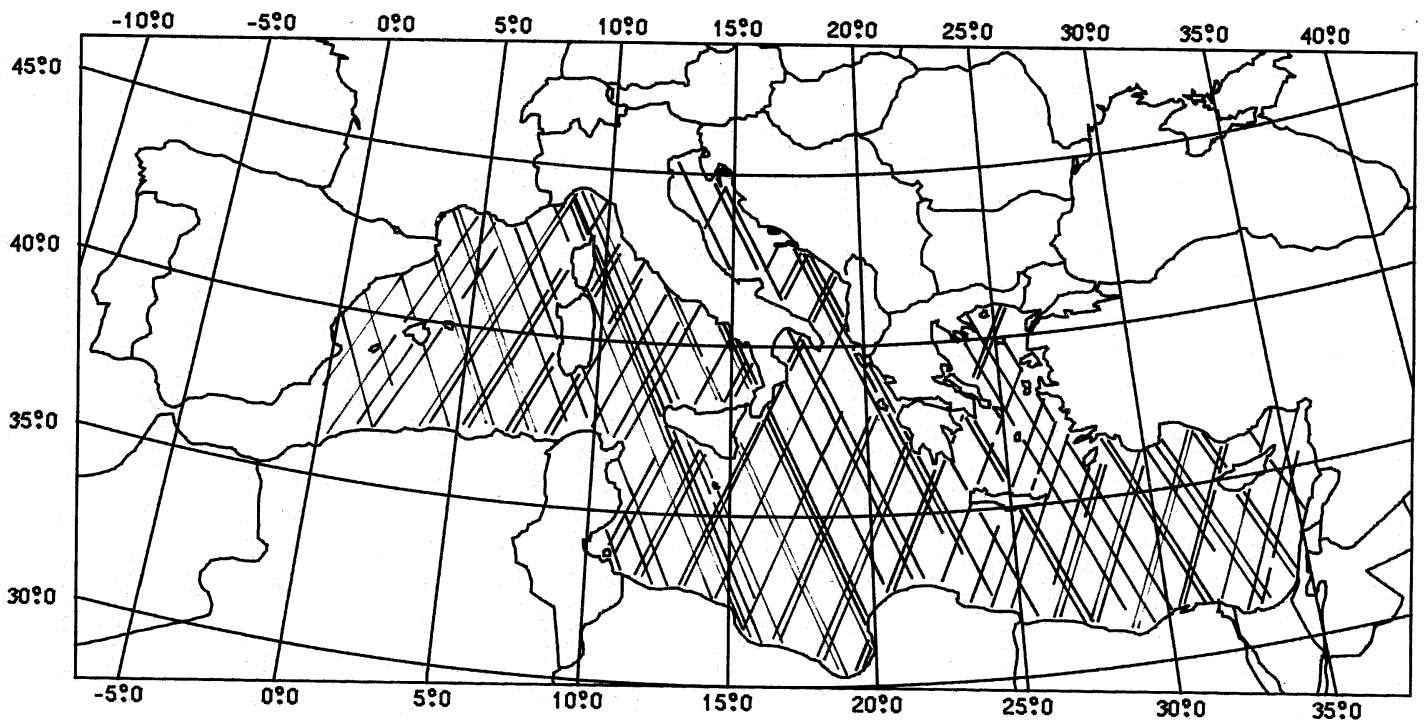

Fig. 3. Footpoints of Seasat observations on the Mediterranean sea.

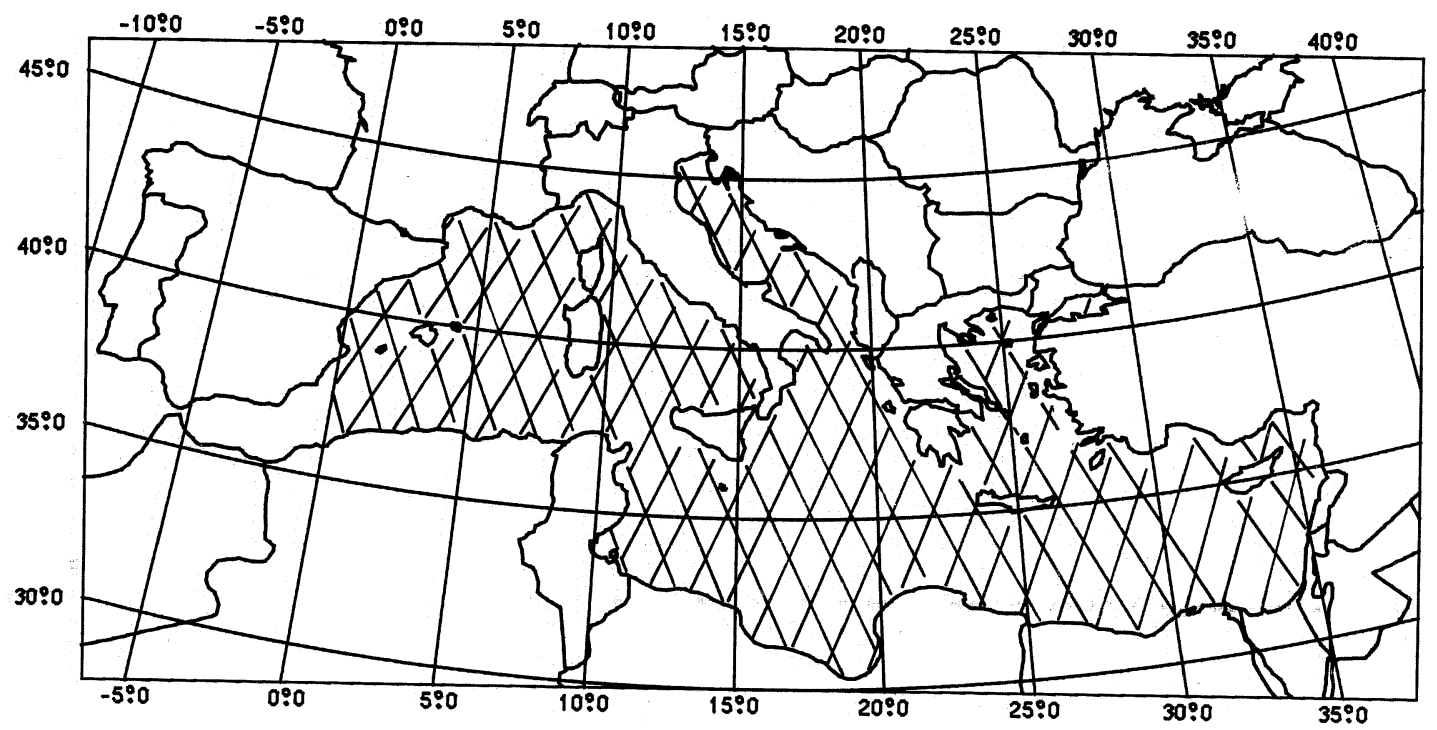

Fig. 4. Footpoints of Geosat observations on the Mediterranean sea. 


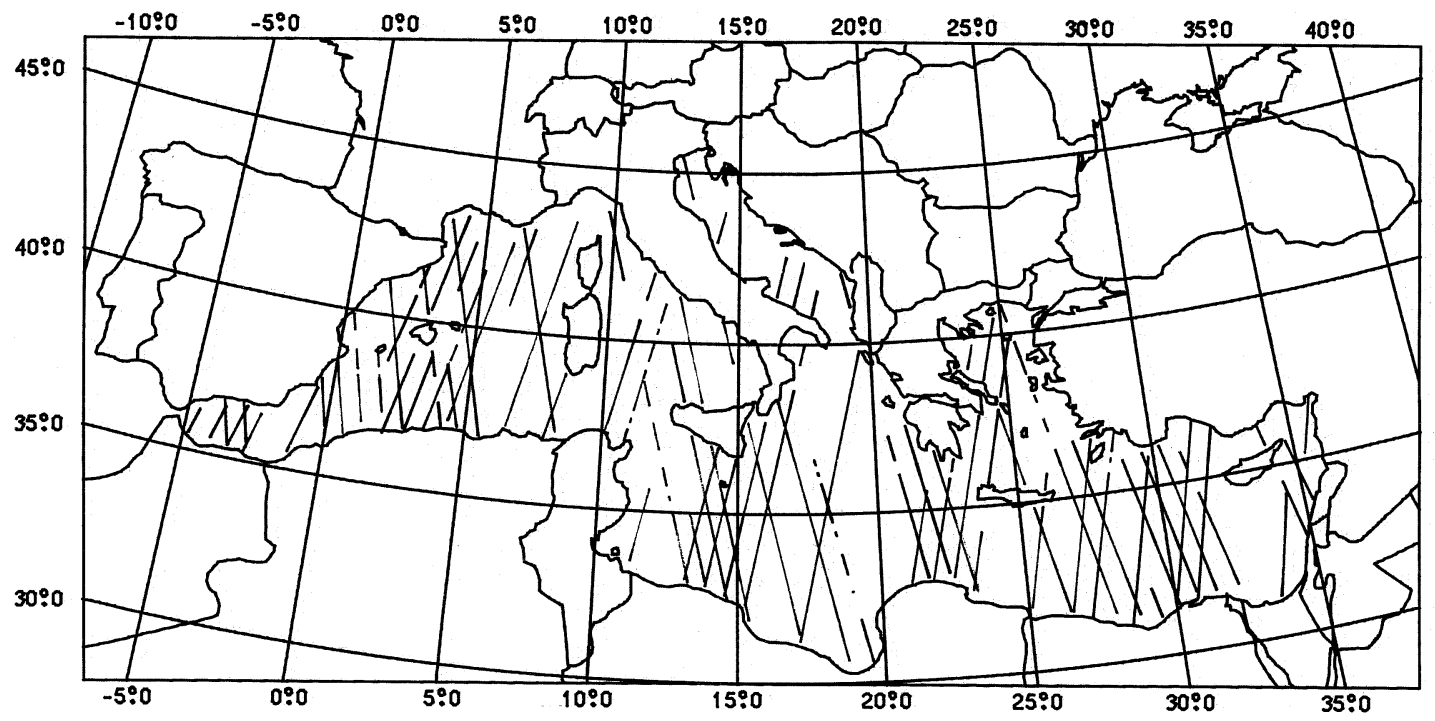

Fig. 5. Footpoints of ERS1 observations on the Mediterranean sea during the 35 days repeat mission.

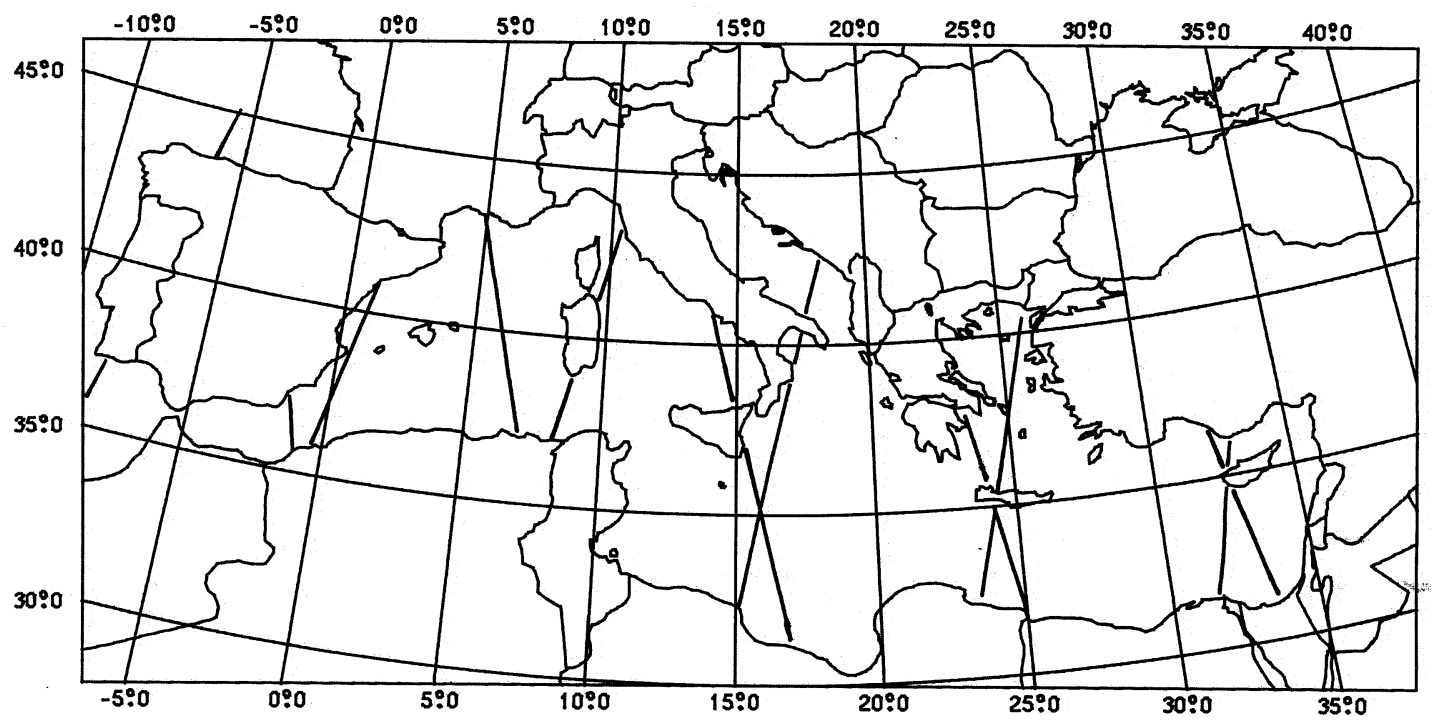

Fig. 6. Footpoints of ERS1 observations on the Mediterranean sea during the 3 day repeat mission. 

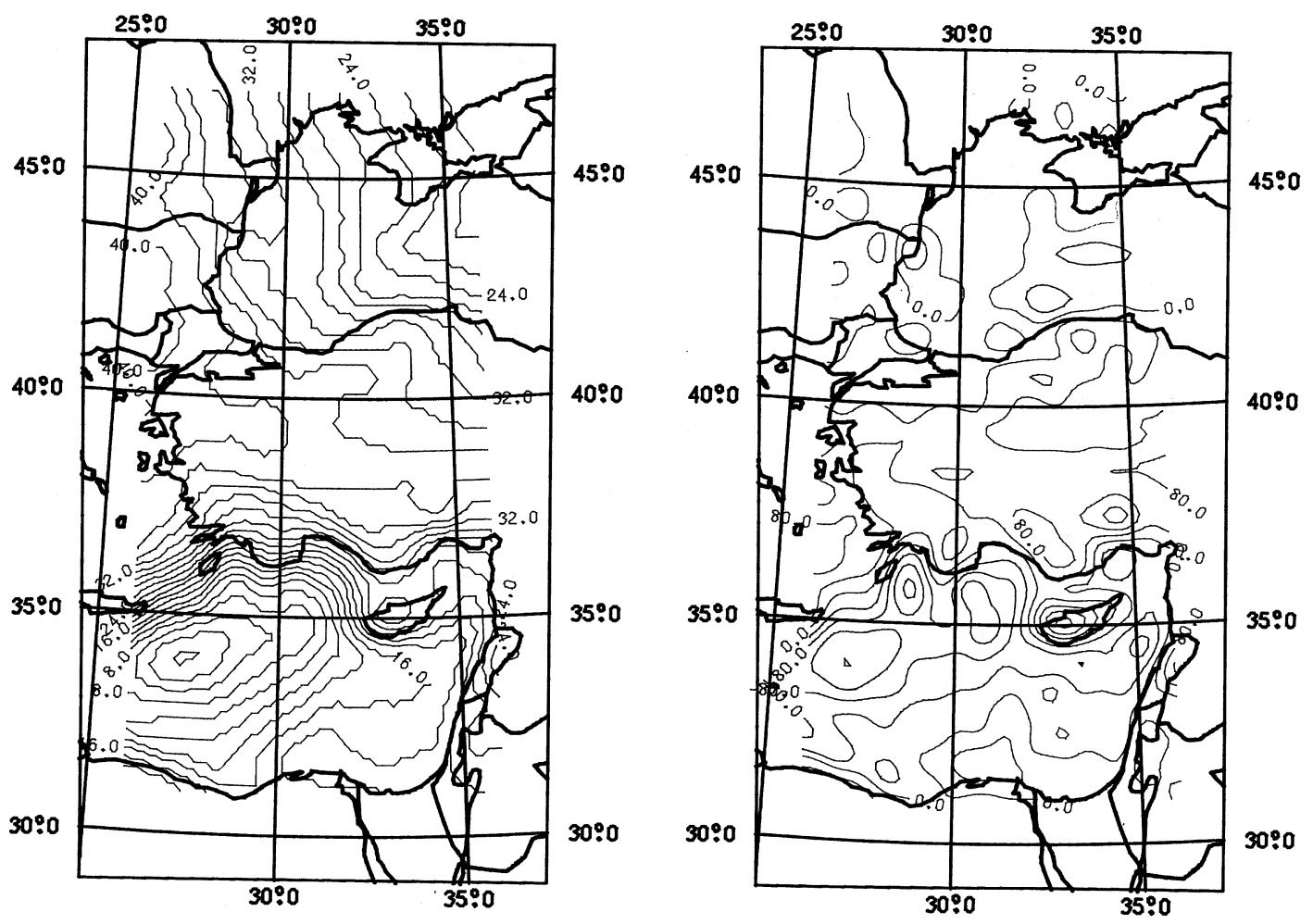

Fig. 7a. OSU91A model in the Eastern Mediterranean area: geoid (on the left, contour interval $=2 \mathrm{~m}$ ) and free air anomalies (on the right, contour interval $=40 \mathrm{mGal}$ ).

of the signal by further subtracting the effect of the Residual Terrain Modelling, $\Delta g_{t}$, (Forsberg, 1985) i.e. the high frequency part of the Terrain correction.

We are therefore left with a residual field

$$
\Delta g_{r}=\Delta g_{F}-\Delta g_{M}-\Delta g_{t}
$$

which is both smooth and regionalized and it is generally this field to which we apply a proper operator transforming it into an estimate of the anomalus potential $T_{r}$. As a final step we add back to $T_{r}$ the contribution of the global model, $T_{M}$, that of the RTM, $T_{t}$, to obtain a final estimate of the geoid through

$$
N=\frac{1}{\gamma}\left(T_{r}+T_{M}+T_{t}\right)
$$

Just to give an idea, the model undulation
$N_{M}$ is of the order of $(45 \pm 3) \mathrm{m}$ in the Western Mediterranean (but it goes down to $(10 \pm 5) \mathrm{m}$ in the eastern part) while the topographic correction $N_{t}$ and the residual part $N_{r}$ are of the order of $1 \mathrm{~m}$.

\subsubsection{Stokes formula by FFT}

Two test computations have been performed by this method which is nothing but the application of the Stokes formula, to the window where we have data, computed by the FFT techniques exploiting its shape of a quasi-convolution (Sideris, 1987; Strang van Hees, 1991).

Of the two geoids computed, the first one refers to the Western Mediterranean $\left(0^{\circ} \leq \lambda \leq 10^{\circ} ; 37^{\circ} \leq \phi \leq 50^{\circ}\right)$, and it has been computed by the Milan group, the other one refers to the Eastern Mediterranean 


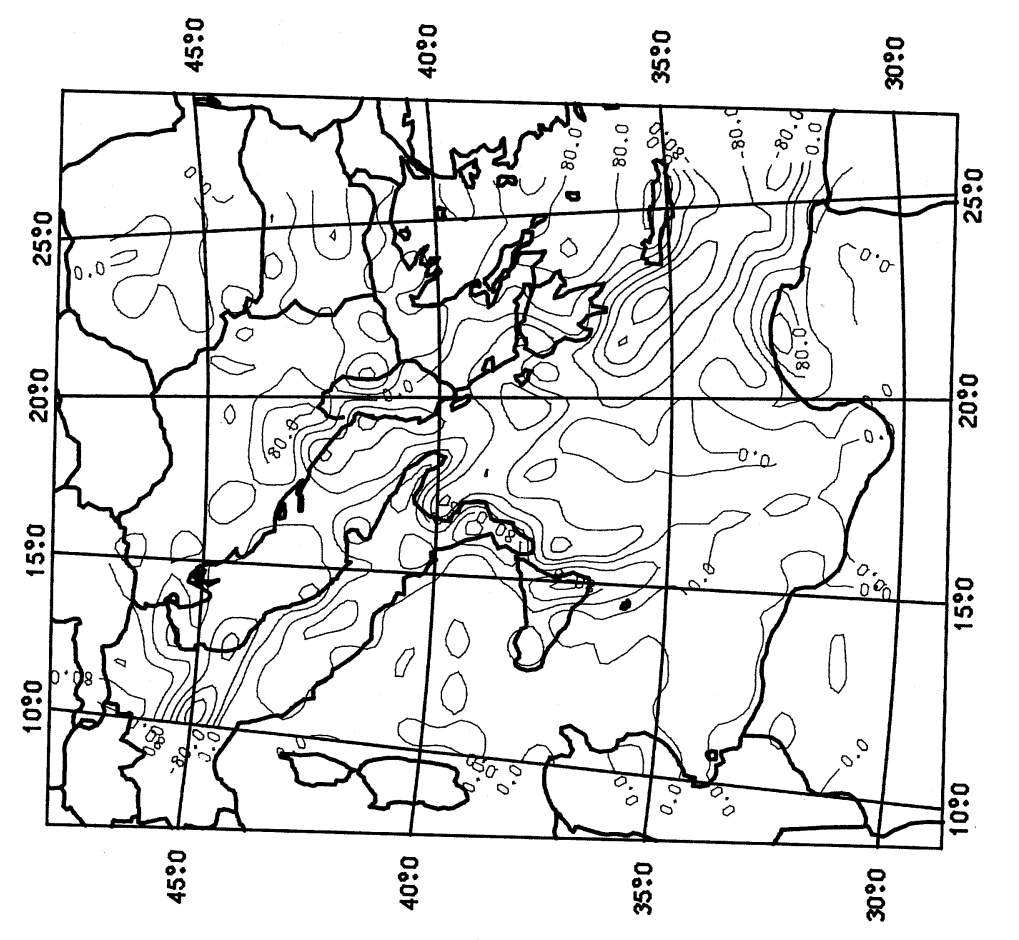

焉

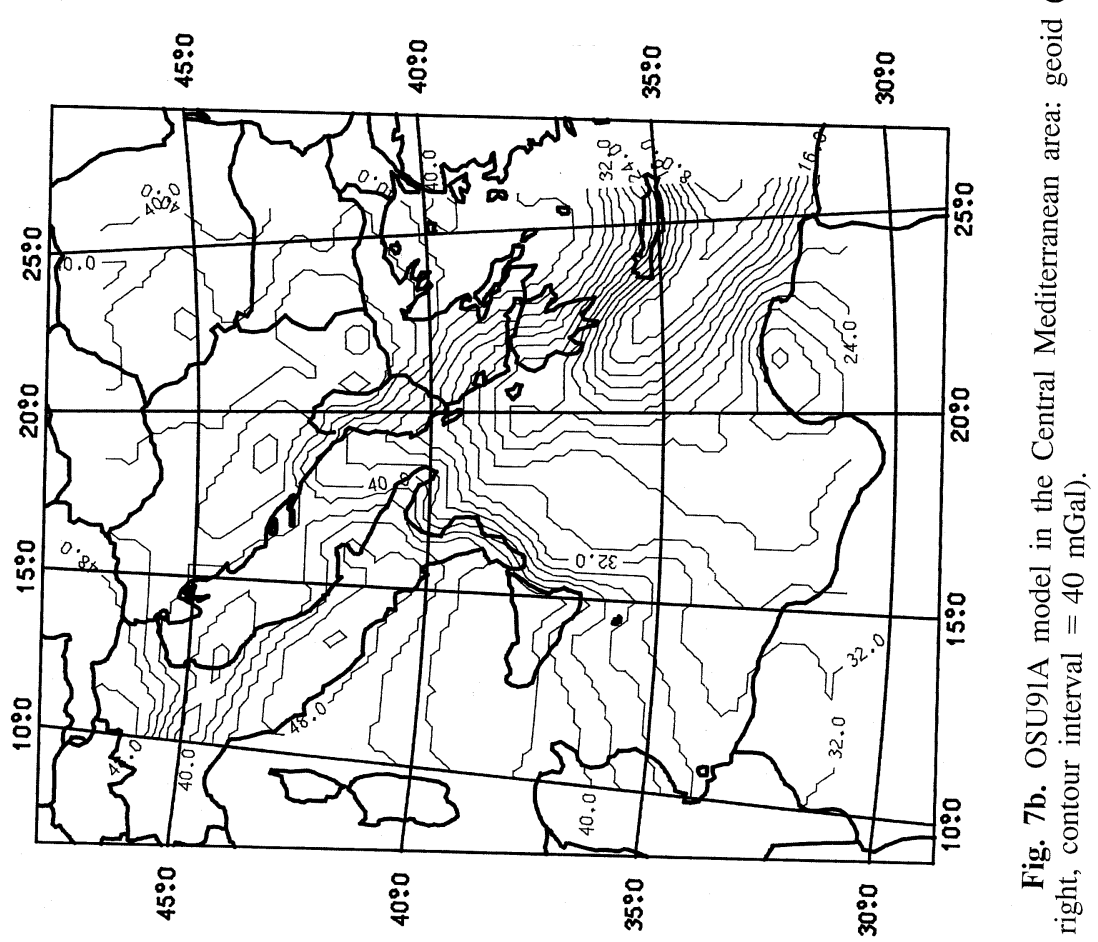




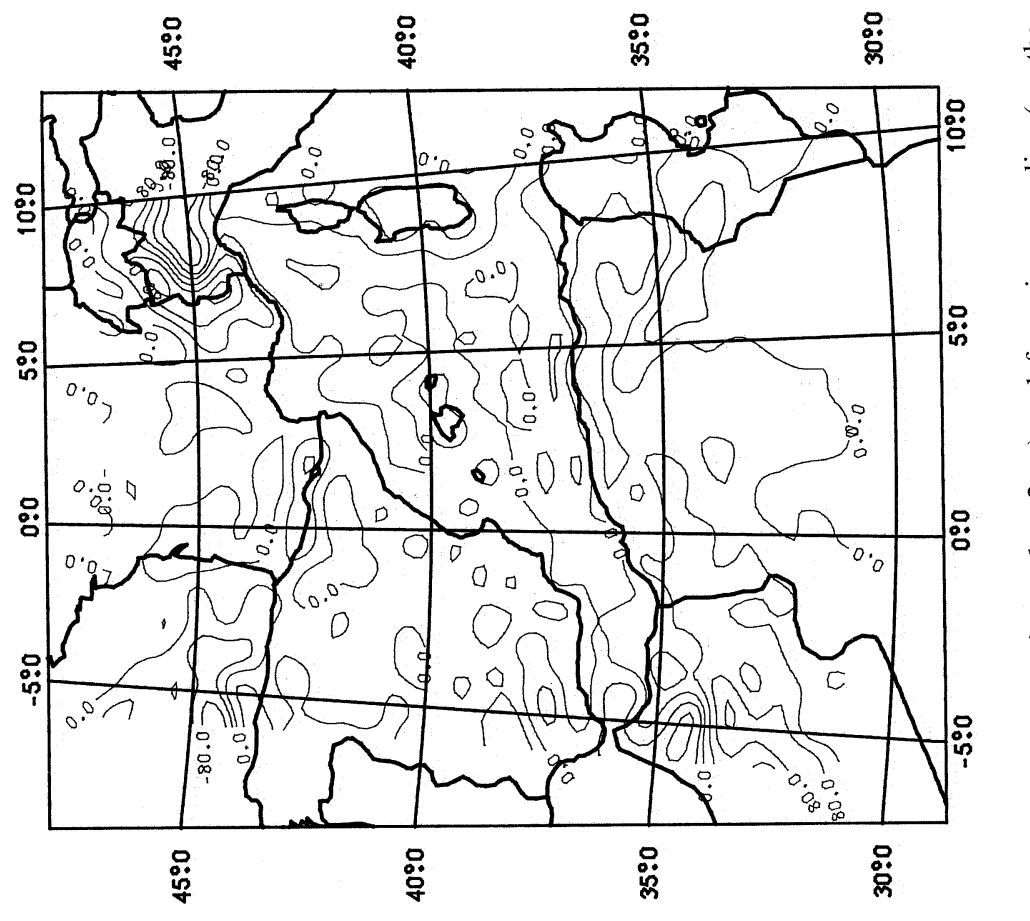

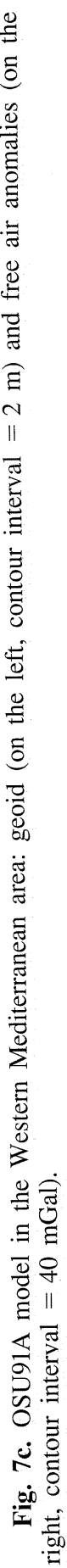


$\left(14^{\circ} \leq \lambda \leq 25^{\circ} ; \quad 34^{\circ} \leq \phi \leq 40^{\circ}\right)$ and it has been computed by the Thessaloniki group, both for the purpose of comparison with the results obtained by other techniques.

The result of the experiment in the Eastern Mediterranean is displayed in fig. 8 .

\subsubsection{Collocation}

One of the drawbacks of this approach was, till a few time ago, its limited capacity of treating a large number of points simultaneously ( $\sim 3000$ points $)$ since the method implies the solution of a system of as many equations as points, with a completely filled in normal matrix. Fortunately enough we have now a technique (Bottoni and Barzaghi, 1993) which allows a very fast solution even for very large systems of this kind on condition that the data be regularly gridded, so that a suitable combination of Toeplitz and FFT methods can be applied.

A large experiment with 17557 points has been performed in the Western Mediterranean by the Copenhagen and Milan groups (fig. 9), comparing these results with those obtained with the Stokes/FFT approach. The comparison is satisfactory, since the mean square difference between the two geoids is $13 \mathrm{~cm}$ compared with $66 \mathrm{~cm}$ of signal. These numbers ignore the $45 \mathrm{~cm}$ of bias due to the fact the FFT techniques work with data referred to their average.

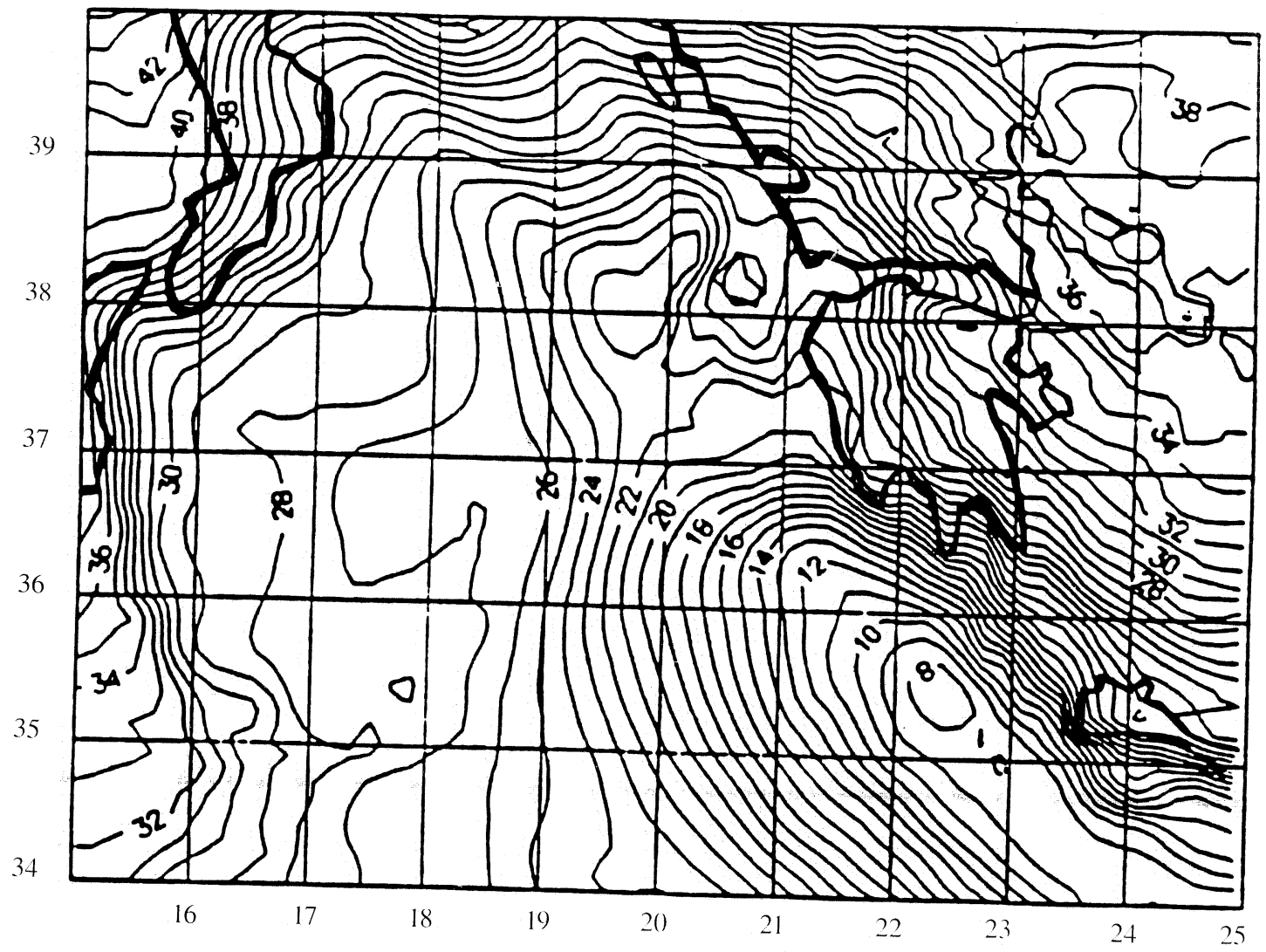
Fig. 8. Geoid computed by FFT techniques in the Eastern Mediterranean area within Geomed Project
(contour interval $=1 \mathrm{~m}$ ). 


\subsubsection{Pure collocation}

Since in open sea the topographic correction is not so strong and rough, in this case it is conceivable to perform a geoid computation by pure collocation, i.e. with no remove and restore of the topographic effects, with the main concern that the estimate will not be very accurate in coastal regions.

When the data are treated in their original locations no fast algorithm is available, so that the computational burden has to be controlled by limiting the area of computation. The Madrid group has estimated a geoid in this way on the Mediterranean by splitting it into 330 $\left(1^{\circ} \times 1^{\circ}\right)$ zones on each of which the prediction was performed from a $\left(2^{\circ} \times 2^{\circ}\right)$ block covering the estimation area. The computed geoid is displayed in fig. 10. The prediction error is in most cases around $5 \mathrm{~cm}$, apart from some coastal regions where it grows to tens of centimeters.

\subsection{An integrated approach}

This approach, pushed by the Thessaloniki group, is essentially a full collocation procedure, with adjustment of parameters, applied to the set of equations

$$
\left\{\begin{array}{l}
h=\frac{1}{\gamma} T+(a \lambda+b)+\varepsilon \\
\Delta g=-\left(\frac{\partial T}{\partial r}+\frac{2}{r} T\right)+\eta
\end{array}\right.
$$

The interesting point in (3.7) is specially that the density of data referring to the anomalous potential is extremely increased by the

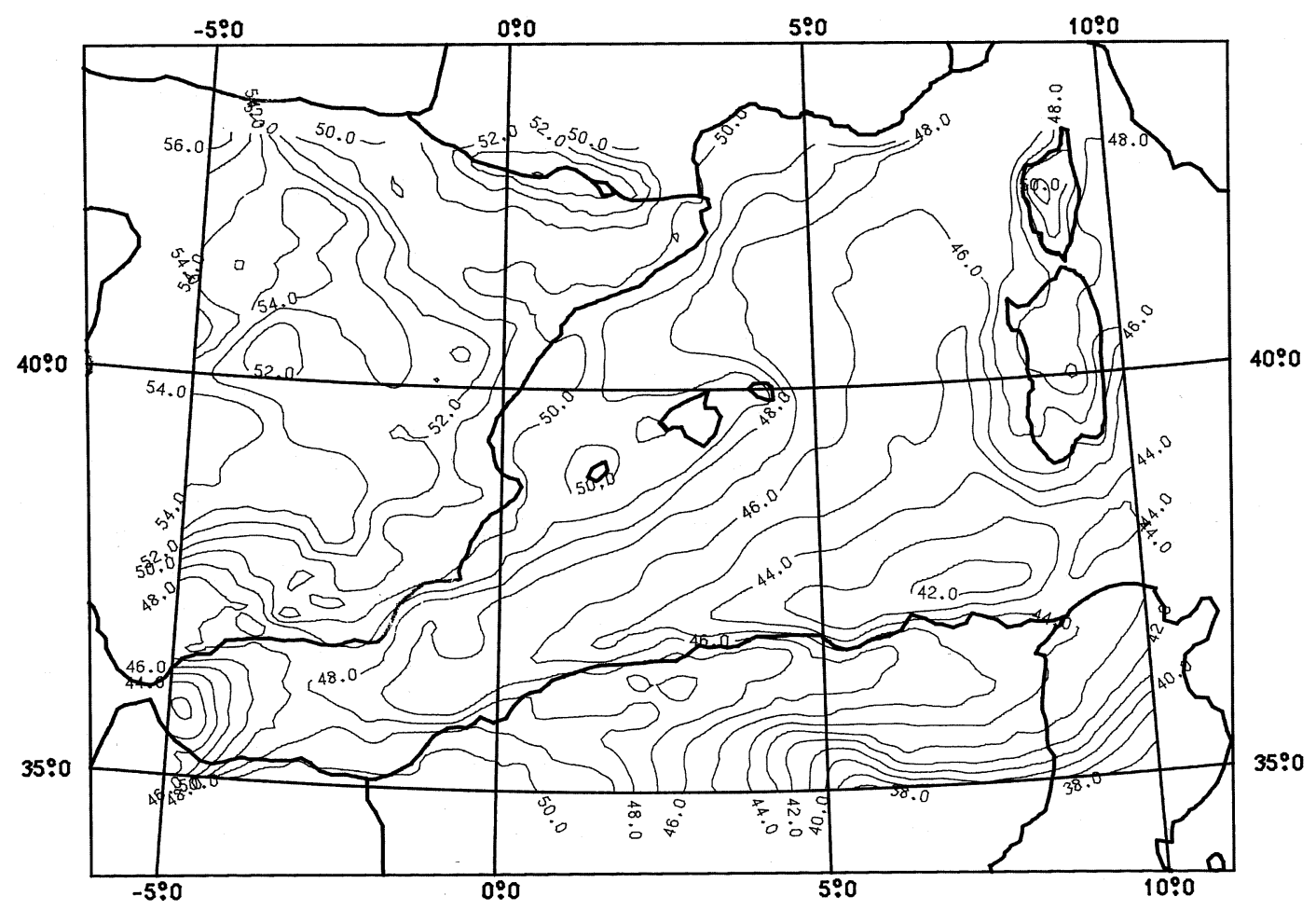

Fig. 9. Geoid computed by fast collocation in the Western Mediterranean area within Geomed Project (contour interval $=1 \mathrm{~m})$. 


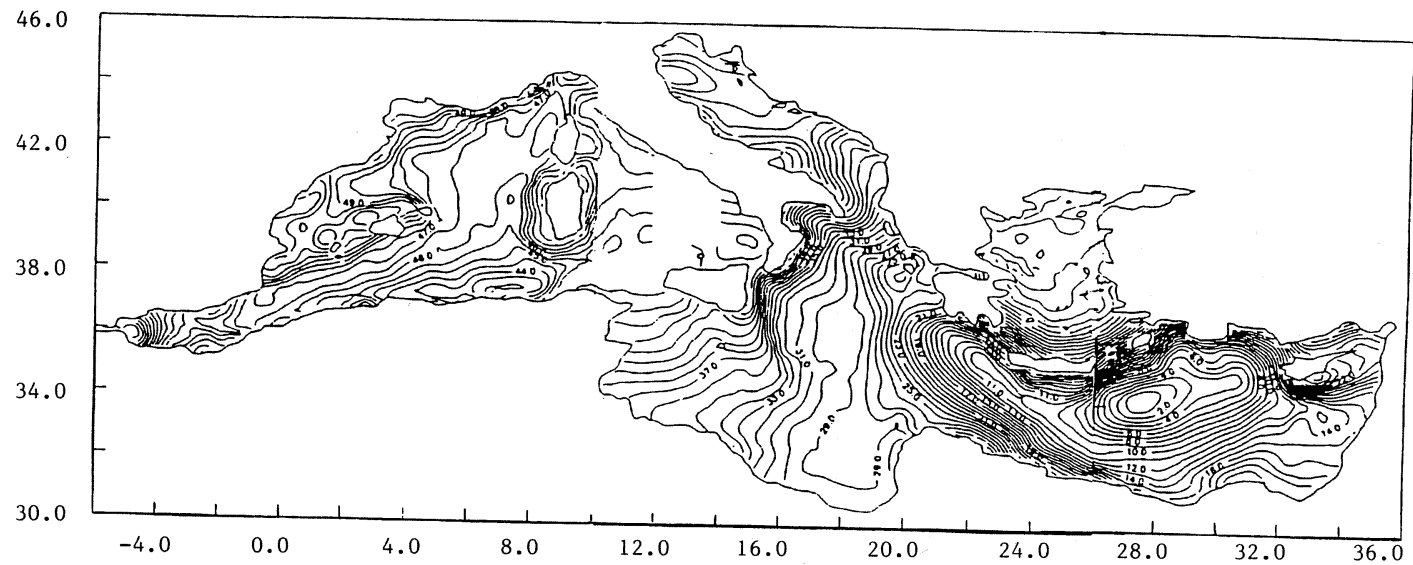

Fig. 10. Geoid computed by pure collocation in the Mediterranean sea.

altimetric observations, thus filling the gaps of marine geodesy. Whence the accuracy of the estimate of the geoid should be better. On the other hand in (3.7) the sea surface topography is disappeared, which means that in part it will enter naturally in $(a \lambda+b)$, giving rise to a bilinear surface and in part it can deform $T$, i.e. the geoid. The first part is certainly the biggest one and probably a bilinear model for a window like $26^{\circ} \leq \lambda \leq 36^{\circ} ; 31^{\circ} \leq \phi \leq 37^{\circ}$, is good for it, as one would infer from a global model of SST like the one by Rapp (Rapp, 1989a); the second part, though smaller, is of interest but not available in this approach.

Anyway the internal consistency of the results is certainly very good as it has been tested by leaving 73 altimetric heights $h$ out of the treatment and then comparing them with quantities predicted in the processing. The differences between the two turned out to be zero in the average (as it ought) and have a s.d. of $4 \mathrm{~cm}$.

\subsection{The sea surface topography}

One of the crucial questions of this project is: do we really believe that the accuracy of our data and the reliability of our models are sufficient to produce a significant estimate of the SST?

In Western Mediterranean we have com- puted a SST by subtracting the gravimetric geoid from the altimetric one; the result is shown in fig. 11. As one can see we have a surface waving from $-0.80 \mathrm{~m}$ along the African coast to $-0.20 \mathrm{~m}$ along France and 0.20 $\mathrm{m}$ in Cataluña. These variations seem to be certainly higher than the noise we expect in each geoid, which is of the order of $5 \mathrm{~cm}$ for both of them. However we are not yet able to say, whether there are undetected systematic effects distorting our solutions.

\section{Comparisons}

There are two possibilities of making external checks of our data; namely either we compare them with independent data of the same kind but coming from different sources, or we try to compare with other geophysical fields exploiting some mutual relation with the gravity field.

Only little work has been done till now in this field, yet we like to mention:

a) geoids comparisons: an external comparison has been performed between the Geomed geoid in the Western Mediterranean and another gravimetric geoid supplied by the $\mathrm{Bu}$ reau Gravimetrique International. This last has been computed (Barriot, 1987) over a large window $\left(-15^{\circ} \leq \lambda \leq 28^{\circ} ; 25^{\circ} \leq \phi \leq 55^{\circ}\right)$, by 


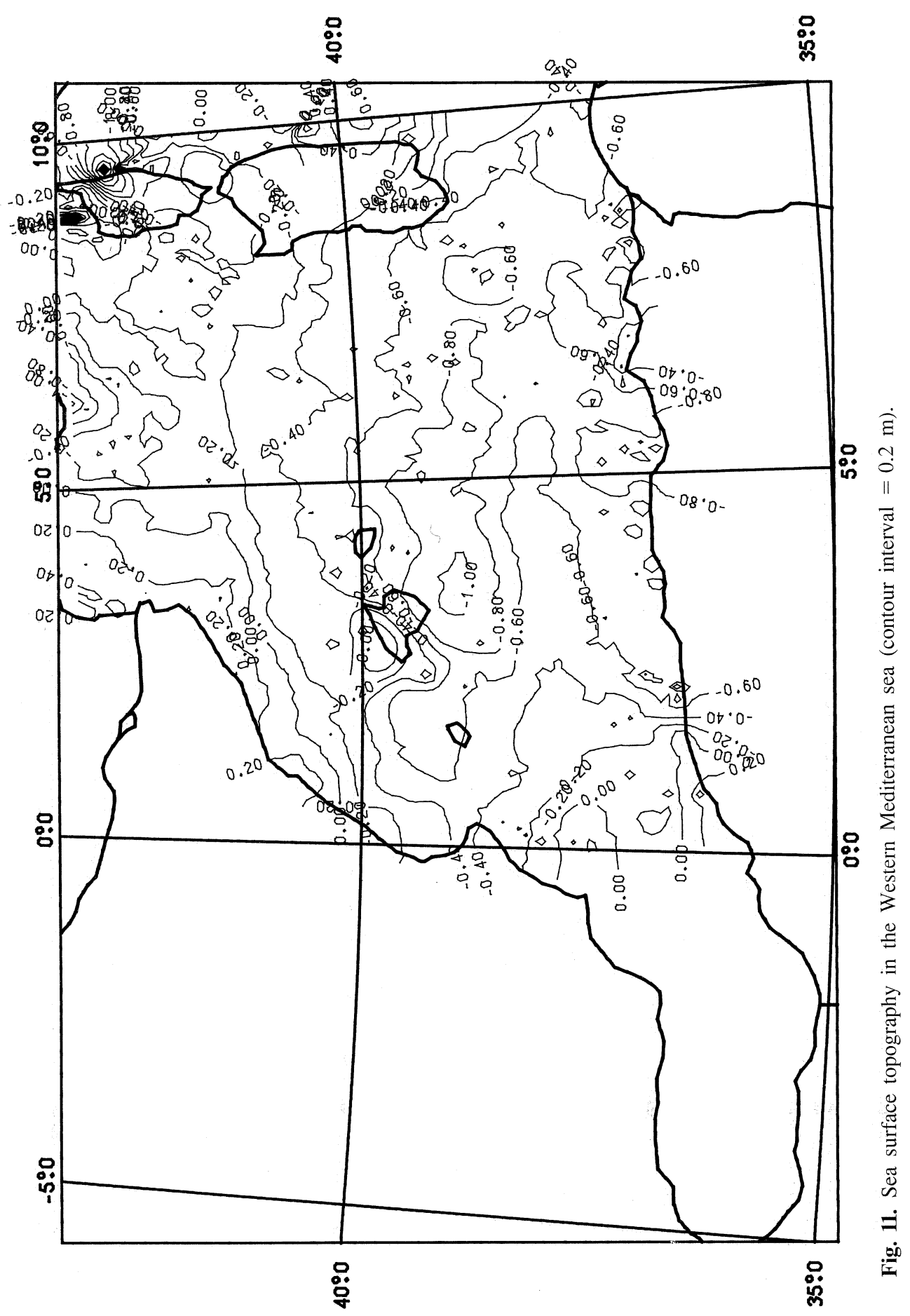


applying a truncated Stokes formula with a $6^{\circ}$ cap. Terrain effects have not been considered (fig. 12). The difference, on 17557 points, shows that there is a bias of $0.49 \mathrm{~m}$ and an r.m.s. of $0.81 \mathrm{~m}$. This suggests rather pessimistic conclusions. However by looking at the contour plot of these differences (fig. 13) we find they are quite flat in the marine area and they become very high and systematic (only positive signs) on land; this could be attributed to the different treatment of the contribution of topography. In particular, we believe that in Corse, where we have the maximum differences, there might be a problem with the gravity data;

b) isostatic topographic corrections: some work has been done by applying different isostatic-topographic corrections to the field of free air gravity anomalies, to verify which one would produce the best smoothing and homogeneization of the gravity field.
The Moho depths used in the computation have been derived from the Airy-Heiskanen theory or an improved version of it; another Moho model was derived from the analysis of seismic data. By using the Central Mediterranean as a test area, it has been proved by the Graz group that the Airy-Heiskanen corrections have a much better performance, while the seismic Moho produces very large discrepancies in the Southern Sicily and along the Calabrian arc.

\section{Discussion}

The following points represent the goals defined by the Geomed groups for the next period:

a) new data: in particular it seems essential to acquire new gravity data, may be not at

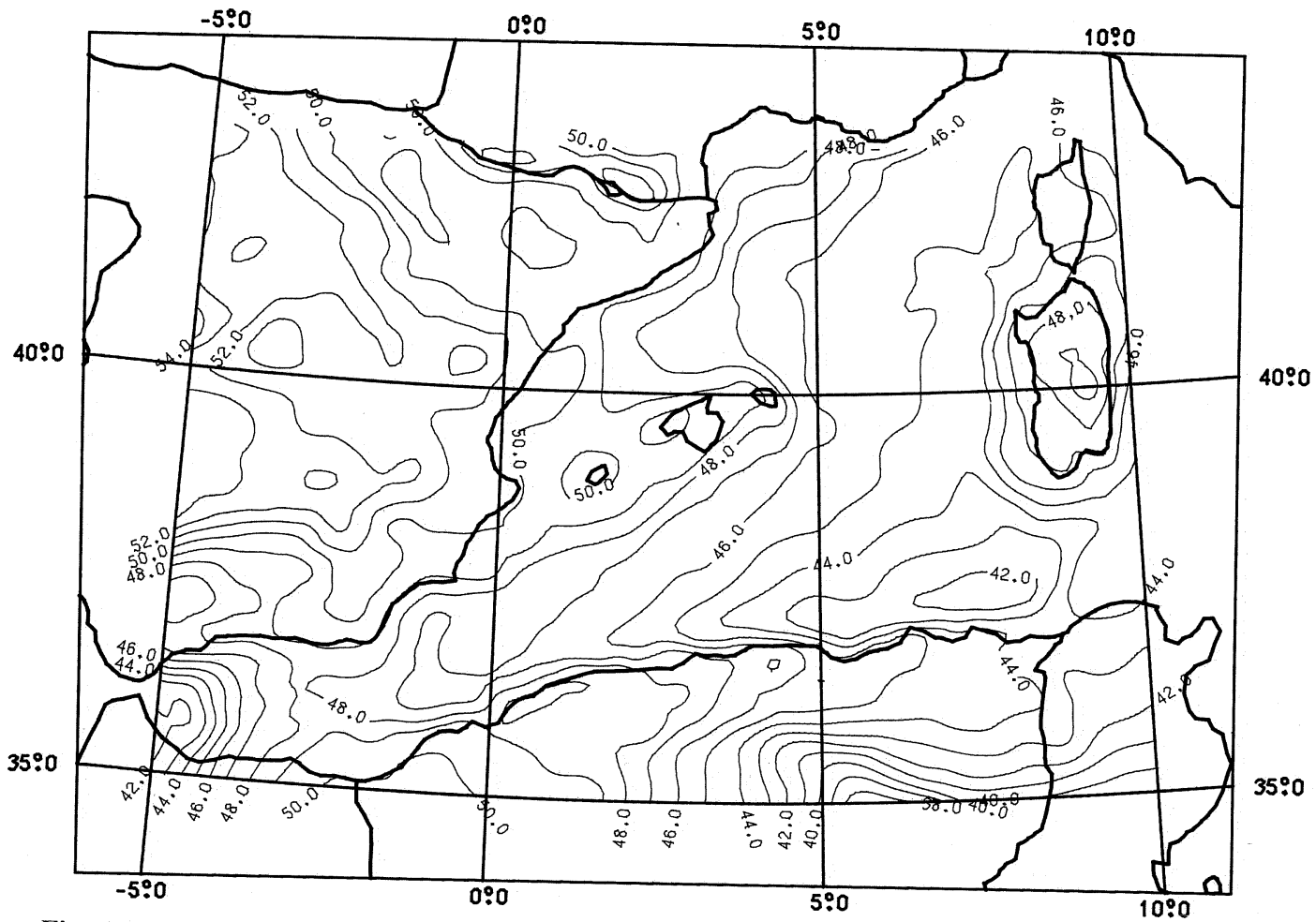

Fig. 12. Gravimetric geoid in the Western Mediterranean area computed by the Bureau Gravimetrique (Barriot, 1987) (contour interval $=1 \mathrm{~m}$ ). 


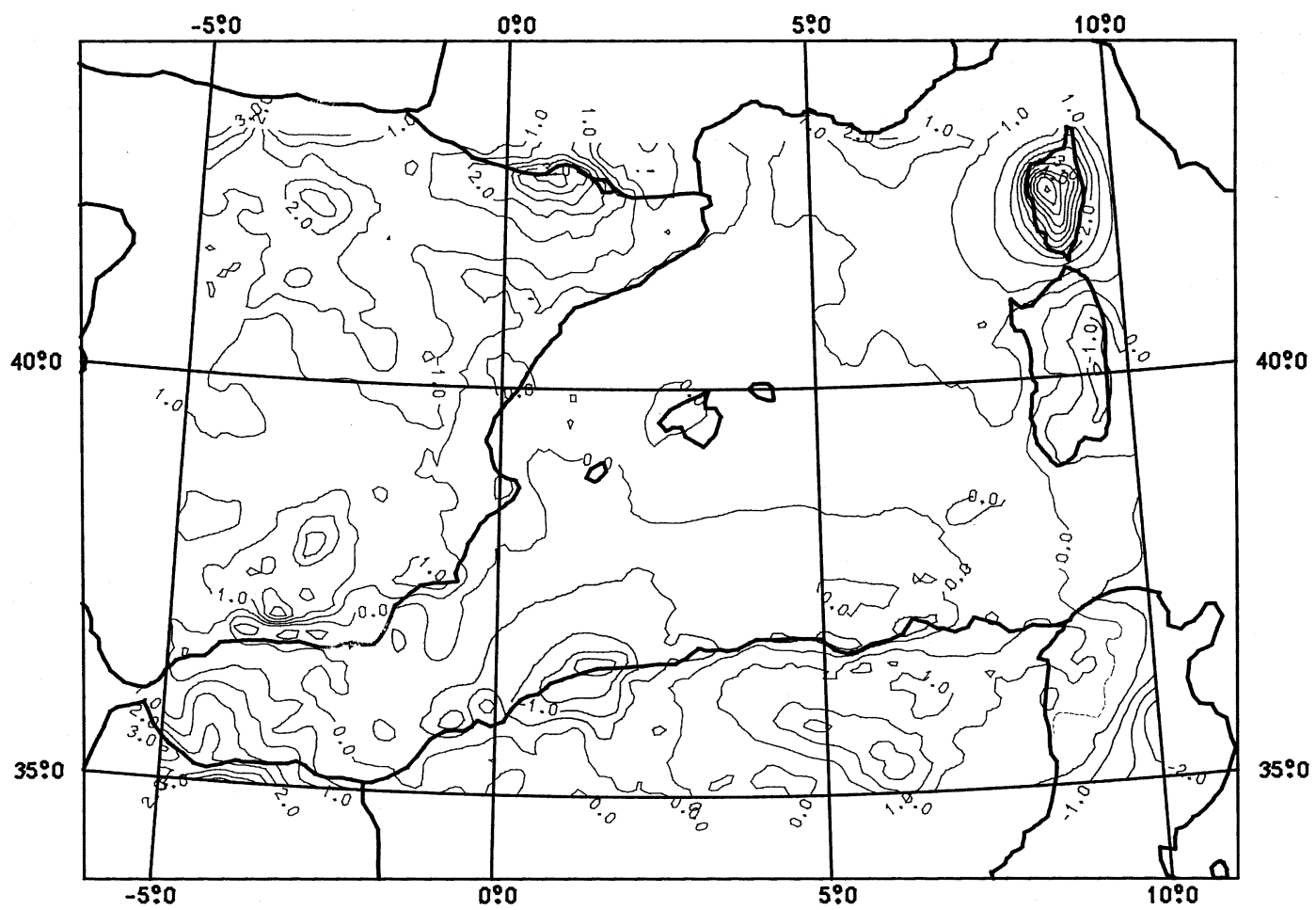

Fig. 13. Differences between Geomed geoid and the geoid supplied by the BGI in the Western Mediterranean (contour interval $=0.5 \mathrm{~m}$ ).

a high resolution, in North Africa and in France, Croatia, Turkey, etc. It has also been decided to collect GPS data, levelling data and deflections of the vertical, particularly along the coasts;

b) validation: a project has been established to validate our marine gravity data sets with gravimetric profiles owned by DMA; very essential is the validation of ETOPO5U by comparing it with Morelli's bathymetry as well as with national DTM's; meanwhile the new ERS1 data will be validated and included in the altimetric adjustments;

c) new computations: the computation of the geoid and SST in the Central Mediterranen will be completed in one year.

After these intermediary goals will be reached we will have at least a geoid and a SST over the whole Mediterranean.
The problems at that point will be to homogenize the solutions and to proceed to their interpretation at least in terms of geostrophic circulation.

\section{Acknowledgements}

This work is the product of a joint effort of many research groups who asked the authors to write this paper in order to advertise the project and its first achievements. We therefore thank C.C. Tscherning, P. Knudsen, R. Forsberg, O. Remmer (Copenhagen); M. Veermer, M. Poutanen (Helsinki); M.J. Sevilla, R. Vieria, A. Gil, G. Rodriguez-Caderot, J. Otero (Madrid); R. Barzaghi, M.A. Brovelli, F. Sansó (Milan); W. Fuerst, W.D. Schuh, H. Suenkel (Graz); D. Arabelos, I. Tziavos (Thessaloniki). 


\section{REFERENCES}

Allan, T.D. and C. Morelli (1971): A geophysical study of the Mediterranean sea, Boll. Geofis. Teor. Appl., 13, 50.

Arabelos, D. (1980): Untersuchungen zur gravimetrischen Geoidbestimmung, dargestellt am Testgebiet Griechenland, Wissenschaftliche Arbeiten der Fachrichtung Vermessungswesen der Universität Hannover, 98 (XIV), 151.

Arabelos, D., P. Knudsen and C.C. Tscherning (1987): Covariance and bias treatment when combining gravimetry, altimeter and gradiometer data by collocation, presented intersection symposium «Advances in Gravity Field Modelling», XIX General Assembly IAG, Vancouver, Canada, August 1987, in Proceedings of the International Association of Geodesy (IAG) Symposia, II, 443-454.

Arabelos, D. and C.C. TsCherning (1988): Gravity field mapping from satellite altimetry, sea-gravimetry and bathymetry in the Eastern Mediterranean, Geophys. J. Int., 92, 195-206.

Arabelos, D. and I.N. Tziavos (1989): The Hellenic geoid - new considerations and experiences, Ricerche $d i$ Geodesia Topografia e Fotogrammetria. Miscellanea per il 70' di Giuseppe Birardi, Milan,, 1-20.

Balmino, G. (1993): Orbit choice and the theory of radial orbit error for altimetry, in "Satellite Altimetry in Geodesy and Oceanography», Lecture Notes in Earth Sciences (Springer-Verlag), 50.

BARRIOT, J.P. (1987): La détermination du geoide par altimetrie océanique et gravimetrie. Quelques aspects du traitement et interprétation géologique sur l'Océan Indien (partie Nord-Ouest) et Méditerranée Occidentale, $\mathrm{PhD}$ thesis, Académie de Montpellier, Université des Sciences et Techniques du Languedoc.

BArzaghi, R., M.A. Brovelli and F. SANsó (1990): Altimetry rank deficiency in crossover adjustment, in Determination of the geoid: present and future, IAG Symposya, 106 (Springer-Verlag), 108-118.

Barzaghi, R., M.A. Brovelli and P. KNudsen (1991): Different crossover adjustments in the Mediterranean area, Boll. Geofis. Teor. Appl., 13 (130-131).

BotToni, G.P. and R. BARZAGHI (1993): Fast Collocation, Bull. Geod., 67 (2).

Brovelli, M.A. and F. Migliaccio (1993): The direct estimation of the potential coefficients by biorthogonal sequences, in "Satellite Altimetry in Geodesy and Oceanography», Lecture Notes in Earth Sciences (Springer-Verlag), 50.

FORSBERG, R. (1985): Gravity field terrain effect computation, Bull. Geod, 59, 342-360.

Knudsen, P. and M.A. Brovelli (1993): Co-linear and cross-over adjustment of GEOSAT ERM and SEASAT altimeter data in the Mediterranean area, Survey in Geophysics, 14 (4-5).

Morelli, C. (1970): Physiography, gravity and magnetism of the Tyrrhenian sea, Boll. Geofis. Teor. Appl., 13, 275-309.

Morelli, C., M. Pisani and C. Gantar (1975a): Geo- physical anomalies and tectonics in the Western Mediterranean, Boll. Geofis. Teorica Appl., 17, 67.

Morelli, C., C. Gantar and M. Pisani (1975b): Bathymetry, gravity and magnetism in the strait of Sicily and the Jonian sea, Boll. Geofis. Teor. Appl., 17, 3958.

Morelli, C., C. Gantar and M. Pisani (1975c): Geophysical studies in the aegean sea and in the Eastern Mediterranean, Boll. Geofis. Teor. Appl., 17, 128-168.

RAPP, R.H. (1989a): The treatment of the permanent tidal effects in the analysis of satellite altimeter data for SST, Manuscripta Geodaetica, 14 (6).

RAPP, R.H. (1989b): Combination of satellite, altimetric and terrestrial gravity data, in «Theory of Satellite Geodesy and Gravity Field Determination», Lecture Notes in Earth Sciences, (Springer-Verlag), 261-284.

RAPP, R.H. (1993): Use of altimeter data in estimating global gravity models, in "Satellite Altimetry in Geodesy and Oceanography», Lecture Notes in Earth Sciences (Springer-Verlag), 50.

RaPP, R.H., Y.M. WANG and N.K. PAVlis (1991): The Ohio State 1991 geopotential and sea surface topography harmonic coefficient models, Rep. n. 410, Dept. of Geod. Sc. and Surveying, The Ohio State University, Columbus.

SANSó, F. (1993): Theory of geodetic B.V.P.s applied to the analysis of altimetric data, in "Satellite Altimetry in Geodesy and Oceanography», Lecture Notes in Earth Sciences (Springer-Verlag), 50.

Schrama, E.J.O (1989): The role of orbit errors in processing of satellite altimetric data, Netherlands Geodetic Commission, Geodesy, 33.

SIDERIS, M.G. (1987): Spectral methods for the numerical solution of Molodensky's problem, UCSE Rep. n. 20024, The University of Calgari.

Strang van HeEs, G. (1991): Stokes formula using Fast Fourier techniques in Determination of the geoid: present and future, IAG Symposia, 106 (Springer-Verlag), 405-408.

WAGNER, C.A. (1989): Summer school lectures on satellite altimetry, in «Theory of Satellite Geodesy and Gravity Field Determination», Lecture Notes in Earth Sciences (Springer-Verlag), 285-334.

WANG, Y.M. and R.H. RAPP (1990): Revised Geosat geophysical data records based on the OSU89 orbit improvement for the first year of the ERM, Internal Rep., Dept. of Geod. Sc. and Surveying, The Ohio State University, Columbus.

Wunsch, C. (1993): Physics of the Ocean circulation, in "Satellite Altimetry in Geodesy and Oceanography», Lecture Notes in Earth Sciences (Springer-Verlag), 50.

ZLOTNICKI, V. (1993): Quantifying time - varying oceanographic signals with altimetry, in "Satellite Altimetry in Geodesy and Oceanography», Lecture Notes in Earth Sciences (Springer-Verlag), 50.

(received January 26, 1993; accepted March 20, 1993) 